\title{
Pembangunan Pengetahuan Masyarakat di Sekitar Gunung Api Tentang Risiko Bencana Erupsi
}

\author{
Agus Purnomo \\ Masuk: 26022018 / Diterima: 28062018 / Dipublikasi: 30062018 \\ (c) 2018Fakultas Hukum dan IImu Sosial UNDIKSHA dan IGI
}

\begin{abstract}
This article aims to explain how the responses and perceptions of communities around the Mountain in facing the threat of danger eruption. The results of their responses and their perceptions of disaster studies vary widely. Many variables affect, such as education, dependent burden, gender, age, until disaster experience. Data collection using questionnaire and interview techniques. An interactive model analysis is used to describe interview results. From the analysis it was found that people in Kecamatan Ngantang - Malang who were affected by Kelud eruption in 2014 were not ready to face the disaster because previous years experience never got that way. There is also an opinion from the community in Kediri that Kelud eruption in 2014 is the impact of the struggle for Kelud region with Blitar regency. People in Kecamatan Poncokusumo - Malang respond to the eruption of Mountapi Bromo in 2014 as a destiny and as long as they do good, their village will not be affected by the damage. They strongly believe in good karma and bad karma. If there is one villager in their village who is doing bad things then all villagers will be exposed to wrath from Bromo Volcano. And people in Kabupaten Bondowoso assume that Raung eruption in 2015 will be the same as before and not damage. They did not object if they had to be evacuated or relocated because most of the people living on the slopes of Raung were working for Perhutani and did not feel entirely of the land or cottage. They are residents who already have a place to live in other areas (Sumber Sumber Wringin - Bondowoso).
\end{abstract}

Key words: Disaster Experience; Education; Perception; Response

Abstrak Artikel ini bertujuan untuk menjelaskan bagaimana respon dan persepsi masyarakat disekitarGunungapi dalam menghadapi ancaman bahaya erupsi. Dari hasil studi respon dan persepsi mereka terhadap bencana sangat bervariasi. Banyak variabel yang mempengaruhi, seperti pendidikan, beban tanggungan, jenis kelamin, usia, hingga pengalaman bencana. Pengumpulan data menggunakan teknik angket dan wawancara. Analisis model interaktif digunakan untuk mendeskripsikan hasil wawancara. Dari hasil analisis ditemukan bahwa masyarakat di Kecamatan Ngantang - Malang yang terdampak erupsi Kelud pada tahun 2014 tidak siap dalam menghadapi bencana tersebut karena pengalaman tahun sebelumnya tidak pernah sampai seperti itu. Ada juga pendapat dari masyarakat di Kabupaten Kediri bahwa erupsi Kelud pada tahun 2014 merupakan dampak dari perebutan wilayah Kelud dengan Kabupaten Blitar. Masyarakat di Kecamatan Poncokusumo - Malang menyikapi erupsi Gunungapi Bromo tahun 2014 sebagai sebuah takdir dan selama mereka berbuat baik maka desa mereka tidak akan terkena dampak merusaknya. Mereka sangat percaya dengan karma baik dan karma buruk. Jika ada satu warga saja di desa mereka yang melakukan hal buruk maka seluruh warga desa akan terkena murka dari Gunungapi Bromo. Dan masyarakat di Kabupaten Bondowoso beranggapan bahwa erupsi Raung pada tahun 2015 akan sama seperti sebelumnya dan tidak merusak. Mereka tidak merasa keberatan jika harus dievakuasi atau direlokasi karena sebagian besar warga yang tinggal di lereng Raung bekerja kepada pihak Perhutani dan tidak merasa memeliki lahan atau rumah pondok tersebut sepenuhnya. Mereka adalah warga yang sudah memiliki tempat tinggal di wilayah lain (Kecamatan Sumber Wringin - Bondowoso).

Kata kunci : Pengalaman Bencana; Pendidikan; Persepsi; Respon

\section{Pendahuluan}

Sudah sejak awal peradaban beberapa kelompok manusia tinggal di

Agus Purnomo

Program Studi Pendidikan IImu Pengetahuan Sosial

Fakultas IImu Sosial Universitas Negeri Malang

agus.purnomo.fis@um.ac.id wilayah Gunungapi (Howes. 2004). Tanah subur dan sumber air menjadi daya tarik tersendiri bagi masyarakat. Gunungapi yang masih aktif di Indonesia berjumlah 127 dan 70 diantaranya dikategorikan sangat mengancam (Zamroni, 2011). 
Masyarakat di sekitar lereng Gunungapi Kelud, Bromo, dan Raung sudah sejak lama tinggal di sana. Mereka memiliki pengetahuan dan cara untuk menghadapi lingkungan demi kelangsungan hidupnya (local wisdom) (Maarif, 2012), termasuk bencana erupsi Gunungapi. Respon mereka dalam menghadapi kejadian terbentuk dari pengalaman pengetahuan, pemahaman, dan pemaknaan terhadap setiap kejadian, fenomena, harapan dan masalah yang terjadi di sekitarnya (Vazquez \& Marvan, 2012).

Respon ketika bencana dipengaruhi oleh persepsi terhadap bencana (Sattler, Kaiser, \& Hittner, 2000; Miceli, Sotgiu, \& Settanni, 2008). Pengalaman individu dalam mengahadapi bencana akan meningkatkan pemahaman persepsi terhadap bencana dan menjadi motivasi dalam aksi atau tindakan ketika terjadi bencana (Lindell \& Perry, 2000; Russell, Goltz, \& Bourque, 1995; Tekeli-Yesil et al., 2010). Faktor lain yang berpengaruh adalah karakteristik sosial ekonomi dan demografi. Individu pada tiap-tiap kelompok sosial akan menerima informasi dan mengevaluasi bencana serta mempersiapkan diri menghadapi bencana dengan sumberdaya yang berbeda.

Wanita dan pria juga memberikan respon yang berbeda dalam mengahadapi bencana. Bagaimanapun juga wanita lebih mempersiapkan keluarganya dalam menghadapi bencana dari pada pria (Purnomo, 2015), karena itu mereka memiliki resiko yang lebih besar saat terjadi bencana. Usia juga mempengaruhi tingkat kesiapan terhadap bencana (Mishra \& Suar, 2007). Tapi semakin tua usia semakin kecil kemungkinan terlibat dalam kegiatan dalam mengahadapi bencana (Heller, Alexander, Gatz, \& Knight, 2005). Dan dalam pendidikan baik formal, in formal, dan atau non formal sangat bergantung dari kondisi sosial ekonominya seperti pendapatan, kepemilikan rumah, lama domisili (Reininger et al., 2013).

Jadi ada banyak faktor yang mempengaruhi kesiapan dalam menghadapi bencana seperti, usia, jenis kelamin. Karakteristik sosial ekonomi seperti pendapatan dan pendidikan yang didapatkan baik formal, in formal, dan atau non formal. Pendapatan dan pendidikan dinilai berasosiasi positif terhadap kesiapan dalam menghadapi bencana (Russell et al., 1995), Jadi dengan meningkatkan tingkat sosial ekonomi individu akan meningkatkan kesiapan individu dalam menghadapi bencana baik secara langsung atau tidak langsung.

Pendidikan menjadi kunci utama dalam meningkatkan kesiapan individu dalam menghadapi bencana. Semakin tinggi pendidikan maka tingkat pendapatan cenderung semakin tinggi juga (Muttarakan \& Pothisiri, 2013). Tingkat pendidikan akan mempengaruhi tingkat pengetahuan individu dan membentuk pemahamannya mengenai penilaian terhadap resiko bencana dan bagaimana harus bertindak (Menard, Slater, \& Flaitz, 2011).

Pendidikan mengenai kebencanaan tidak hanya harus dilakukan di dalam sekolah (formal education). Di sekolah pengetahuan mengenai kebencanaan dapat diberikan dalam sebuah pembelajaran di kelas. Sementara dalam masyarakat, pendidikan dapat diajarkan dalam berbagai bentuk (Petal, 2008). Dalam komunitas tersebut terjadi transfer pengetahuan tentang aspek kerentanan, penilaian resiko bencana, dan memberikan alternatif terhadap masalah yang dapat disebarluaskan di keluarga, teman, dan tetangga (Izadikhah, 2004). Individu yangterdidik memiliki kesiapan yang lebih karena mereka mampu mengkases informasi tentang kebencanaan dari berbagai sumber.

Gunungapi Kelud, Bormo dan Raung merupakan produk dari proses 
tumbukan lempeng Indo-Australia yang menghujam ke bawah lempeng Asia tepatnya di sebelah selatan Jawa. Ketiga Gunungapi tersebut merupakan bagian dari deratanGunungapi yang tumbuh dan berkembang di dalam Sub Zona Blitar yang dibatasi gawir sesar Pegunungan Selatan. Secara Administratif ketiga Gunungapi tersebut mencakup beberapa wilayah. Berikut adalah wilayah adminstratifnya.

Tabel1. Lokasi Gunungapi Kelud,Bromo,danRaung

\begin{tabular}{ccc}
\hline No & Gunungapi & Wilayah Administratif \\
\hline 1 & Kelud & Kabupaten Kediri, Blitar, dan Malang \\
2 & Bromo & KabupatenMalang,Probolinggo,danPasu \\
3 & Raung & KabupatenJember,Bondowoso,danBany \\
\hline
\end{tabular}

Sumber:ESDM.2010

Lokasi penelitian berada di Kecamatan NgantangKebupaten Malang untuk Gunungapi Kelud, Kecamatan Poncokusumo Kabupaten Malang untuk Gunungapi Bromo, serta Kecamatan Tlogosari, Sumber Wringin, dan Sempol Kabupaten Bondowoso. Pemilihan lokasi berdasarkan pada karakteristik masyarakat dan dipadukan dengan peta kerawanan bencana. Masyarakat Kecamatan Ngantang Kabupaten Malang dipilih karena minimnya pengalaman dalam mengahadapi ancaman erupsi Gunungapi Kelud. Masyarakat Kecamatan Poncokusumo. Kabupaten Malang dipilih karena kepercayaan etnis Tengger dalam memperlakukan Gunungapi Bromo. Terakhir, Kecamatan Tlogosari, Sumber Wringin, dan Sempol Kabupaten Bondowoso dipilih karena rata-rata tingkat pendidikan yang rendah dan pengalaman yang minim dalam menghadapi ancaman erupsi Gunungapi Raung. Berikut adalah peta lokasi penelitian.

\section{Metode}

Penelitian ini bertujuan untuk bagaimana proses pembangunan pengetahuan dalam merespon bencana erupsi gunungapioleh masyarakat sekitar gunung Kelud, Bromo, dan Raung. Dari paparan rasional yang ada pada awal pembahasan, maka dapat disimpulkan bahwa terdapat dua variabel utama, yaitu pendidikan dan pengalaman bencana (explanatoryvariable) dan responsaat terjadi bencanabencana (respondvariable). Berikut adalah jabaran dari masing-masing variable seperti terlihat pada Tabel 2.

Tabel 2. Jabaran Variabel

\begin{tabular}{|c|c|c|c|c|}
\hline \multicolumn{2}{|r|}{ RespondVariable (Y) } & \multicolumn{3}{|c|}{ ExplanatoryVariable (X) } \\
\hline \multirow{10}{*}{$\begin{array}{l}\text { V } \\
\text { Respon }\end{array}$} & Indikator & $\mathbf{V}$ & & Indikator \\
\hline & tidak ada & \multirow{6}{*}{ Pendidikan } & \multirow[t]{4}{*}{ Individu } & Tidak sekolah \\
\hline & $\begin{array}{l}\text { hanya melihat dan mengikuti } \\
\text { situasi }\end{array}$ & & & Dasar \\
\hline & \multirow{2}{*}{$\begin{array}{l}\text { mempersiapkan perlengkapan } \\
\text { bertahan hidup }\end{array}$} & & & Menengah-Atas \\
\hline & & & & Kuliah \\
\hline & \multirow{2}{*}{$\begin{array}{l}\text { merencanakan prosedur } \\
\text { pengungsian bersama seluruh } \\
\text { keluarga }\end{array}$} & & \multicolumn{2}{|c|}{ Jumlah anggota keluarga } \\
\hline & & & \multicolumn{2}{|c|}{$\begin{array}{l}\text { Proporsi pria dan wanita yang } \\
\text { mengenyam pendidikan }\end{array}$} \\
\hline & \multirow[t]{2}{*}{ memeriksa struktur rumah } & \multirow[t]{3}{*}{$\begin{array}{l}\text { Pengalaman } \\
\text { Bencana }\end{array}$} & \multicolumn{2}{|c|}{$\begin{array}{l}\text { Pengalaman bencana 5-10 tahun } \\
\text { terakhir }\end{array}$} \\
\hline & & & \multicolumn{2}{|c|}{ Pengalaman simulasi bencana } \\
\hline & persiapan lainnya & & \multicolumn{2}{|c|}{$\begin{array}{l}\text { Informasi tentang kebencanaan dari } \\
\text { pihak-pihak terkait }\end{array}$} \\
\hline
\end{tabular}




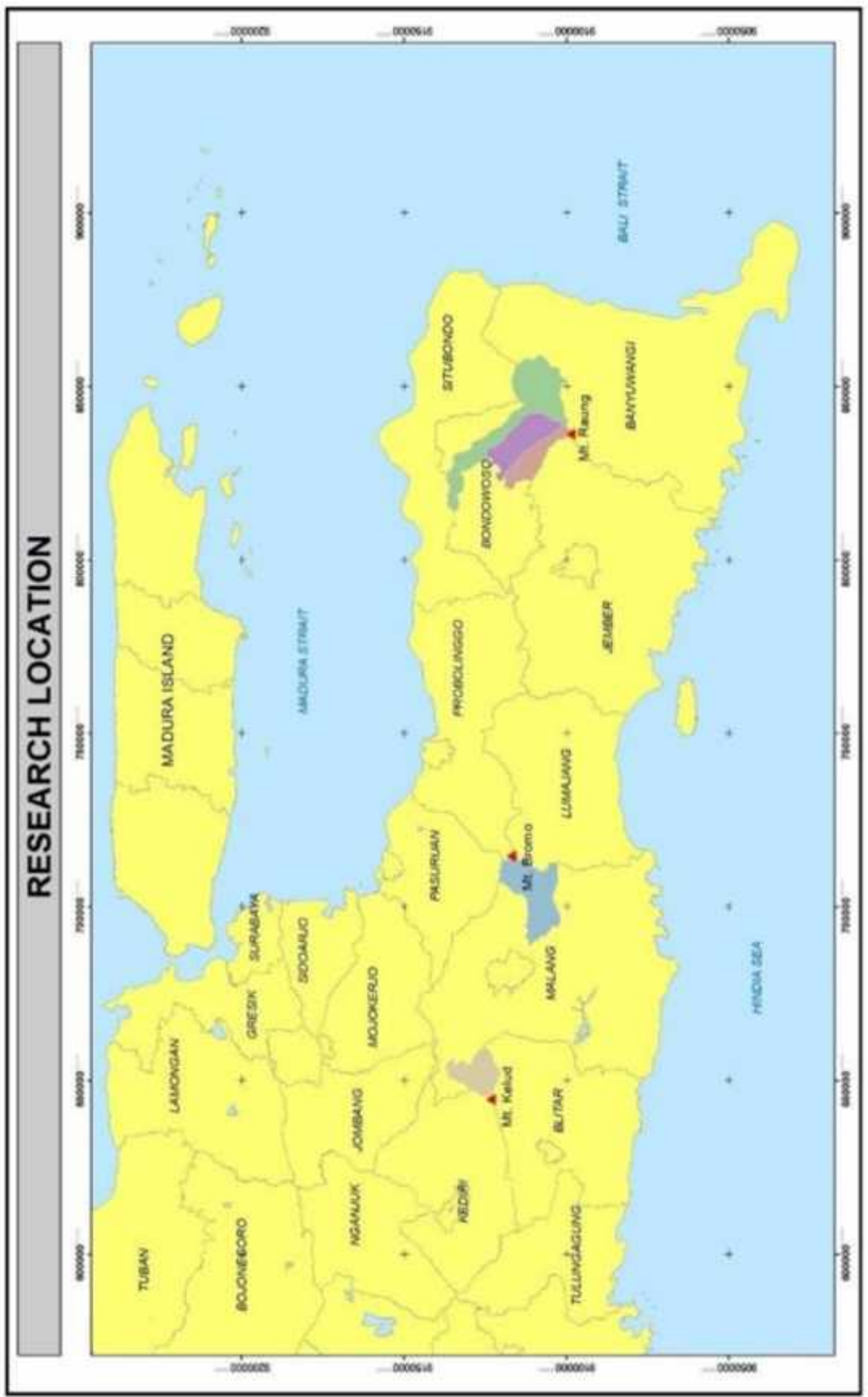

4 | Media Komunikasi Geografi, Vol 19, No. 1, Juni 2018: 1-10 
Explanatoryvariable merupakan nama lain dari Independent variabel atau variabel bebas (Sugiyono, 2012). Penggunaan istilah explanatory merujuk pada variabel terikat ( $\mathrm{Y}$ ) yang merupakan respon dalam menghadapi bencana. Explanatory merupakan variabel yang menjelaskan faktor-faktor apa yang berpengaruh terhadap respon yang diberikan oleh subjek.

\section{Hasil dan Pembahasan}

\section{Pengetahuan tentang Gunungapi}

Masyarakat di sekitar Gunungapi Kelud sudah belajar banyak tentang pola erupsi selamabertahun-tahun. Catatan pada erupsi tahun 1966, 1984, 1990, 2007, dan 2010 sebagian besar memuntahkan material ke arah barat dan barat daya (Kabupaten Blitar dan Kediri). Pengalaman dan pengetahuan yang terbentuk menjadikan pola pikir masyarakat Kecamatan Ngantang Kabupaten Malang yang berada di bagian timur merasa aman dan tidak akan terkena dampak dari erupsi.

Berbeda dengan masyarakat di sekitar Gunungapi Bromo yang memiliki dua pandangan kontradiksi. Satu sisi saat Bromo meletus akan membawa bencana yang mematikan, tapi di sisi lain memberikan kesuburan bagi sumber penghidupan yang mereka miliki. Mereka yang tinggal di sekitar Gunungapi Bromo merupakan percampuran dari budaya Hindu, Budha dan Islam. Mereka percaya bahwa kerugian atau berkah kesuburan yang didapatkan merupakan kekuatan Tuhan. Mereka yakin bila memiliki perilaku baik maka tidak akan mendapatkan karma buruk berupa bencana. Pengetahuan dan keyakinan dalam bentuk mitos ini dikenal luas dan mendapat banyak dukungan, khususnya daerah perdesaan (Dove \& Hudayana, 2011).

Kepercayaan yang terbangun membentuk pengetahuan bahwa erupsi Bromo bukanlah bencana. Tapi peringatan bahwa mereka telah melakukan hal buruk.
Akibatnya warga di Desa Ngadas Kecamatan Poncokusumo tidak merasa takut dengan ancaman erupsi Gunungapi Bromo. Bahkan kegiatan rutin Gunungapi berupa erupsi sudah menjadi bagian dari kegiatan informal warga.

Masyarakat di sekitar Gunungapi Raung membangun pengetahuan tentang ancaman bencana erupsi dari pengalaman erupsi tahun 1956. Banyak warga yang menganggap bahwa erupsi Raung hanya terjadi di dalam kawah dan tidak menimbulkan ancaman. Di Kabupaten Bondowoso hanya beberapa warga yang mau mengungsi saat erupsi tahun 2015. Alasannya adalah lokasi yang mereka tinggali saat ini adalah milik pihak Perhutani, sehingga mereka tidak merasa keberatan untuk meninggalkannya. Warga dengan usia dibawah 40 tahun yang tidakmengalami erupsi tahun 1956 hanya mendapatkan pengetahuan dari informasi yang diberikan oleh Badan Penanggulangan Bencana Daerah (BPBD). Saat hendak melakukan persiapan mengungsi, generasi sebelumnya memberikan informasi bahwa,"Erupsi tidak akan membahayakan, dulu waktu erupsi tahun 1950an kami juga apa-apa. Tenang saja!".

Dari tiga pola masyarakat di atas, dapat disimpulkan bahwa terdapat dua kelompok besar, yaitu kelompok yang membangun persepsi/wacana ancaman erupsi Gunungapi dari pengetahuan lokal, dan kelompok yang membangun persepsi/wacana ancaman erupsi Gunungapi dari pengetahuan modern.

Pada kasus Gunungapi Bromo, masyarakat membangun persepsi dari pengetahuan lokal. Peran dari dukun desa sangat berpengaruh. Setiap keputusan yang diambil oleh pemerintah desa harus mendapatkan persetujuan dari dukun desa. Di Masyarakat Tengger sendiri terdapat empat dukun desa yang masingmasing berada di Kabupaten Malang, Lumajang, Probolinggo, dan Pasuruan. 
Saat dukun ini ditanya tentang pengetahuan untuk memperkirakan apakahBromo akan meletus atau tidak mereka mengaku tidak memilikinya. Mereka hanya meyakini bahwa Bromo tidak akan menyakiti warganya.

Sementara pada masyarakat sekitar Gunungapi Kelud dan Raung membangun persepsi dari perpaduan pengetahuan modern dan agama. Pengalaman erupsi Kelud tahun 2014 dan Raung tahun 2015 membangun kesadaran bahwa mereka tinggal di wilayah rawan bencana. Tapi hanya sedikit yang menganggapnya itu sebagai risiko. Pasca erupsi terjadi, terbentuk satu ikatan yang lebih kuat dalam masyarakat. Mereka yang semulanya melakukan kegiatan agama secara rutin satu bulan sekali, berubah menjadi satu minggu sekali. Mereka yang selamat meyakini bahwa dengan meningkatkan nilai religiusitasnya maka akan terhindar dari bencana di masa yang akan datang (Call, 2012).

\section{Pemaknaan tentang Ancaman Gunungapi}

Pemaknaan bencana erupsi Gunungapi sangat tergantung dari sumber pengetahuan yangada. Meskipun Gunungapi Kelud dan Bromo sering meletus, para pimpinan masih belum meletakkan ancaman ini dalam kehidupan sehari-hari. Di Gunungapi Bromo pandangan pimpinan dan dukun desa sangat berpengaruh terhadap pemaknaan masyarakat. Para pimpinan dan dukun menganggap Bromo adalah tempat yang disucikan. Bencana yang ditimbulkan tidak akan pernah menyakiti mereka. Makna inilah yang diyakini oleh masyarakat di Desa Ngadas.

Para pimpinan dan dukun desa memberi penjelasan kepada warga desa bahwa bencana yang terjadi merupakan peringatan dari Tuhan. Mereka kurang bersyukur atas nikmat yang diberikan. Tidak hanya memaknai bencana erupsi
Bromo. Masyarakat melakukan ritual khusus yang disebut dengan selatan untuk fenomena-fenomena tertentu. Kegiatan tersebut dilakukan di rumah Lurah. Seperti Selataman Balian saat terjadi gerhana bulan/matahari dan SelamatanGalungan saat terjadi gempa bumi.

Makna bahwa Bromo juga sebagai sumber penghidupan juga melekat kuat pada masyarakat Tengger. Tidak ada warga Tengger yang merantau keluar dari desa untuk mencari sumber penghidupan. Mereka yakin bahwa Bromo akan memberikan sumber penghidupan yang cukup bagi mereka. Jika ada warga yang pergi merantau maka akan diusir dari desa. Bromo dalam hal ini memiliki dwi makna. Satu makna sebagai peringatan bahwa mereka kurang bersyukur atas nikmat yang ada. Makna lainnya adalah Bromo sebagai sumber penghidupan.

Kecamatan Ngantang merupakan wilayah yang paling banyak mengalami kerusakan di Kabupaten Malang. Akses menuju Desa Pandansari terputus akibat aliran lahar dingin. Warga di 7 dusun tersebut terlambat mengungsi sehingga beberapa terjebak di rumah saat bencana terjadi. Mereka memaknai bahwa informasi yang diberikan untuk mengungsi atau melakukan persiapan adalah hal yang percuma. Makna ini terbangun dari peristiwa erupsi Kelud tahun2007 dan 2010 yang sama sekali tidak berdampak pada desanya.

Terdapat satu faktor yang sangat kuat di Desa Pandansari saat terjadi erupsi Kelud 2014. Yaitu ketergantungan warga pada ternak (sapi) mereka. Ternak merupakan satu-satunya investasi penting bagi warga desa disekitar lereng Kelud. Ketika kebutuhan untuk melindungi ternak bercampur dengan keyakinan bahwa desa mereka aman. Maka tidak ada alasan yang kuat bagi mereka untuk melakukan persiapan mengungsi atau mengungsi. 
Di Kabupaten Bondowoso memaknai Gunungapi Raung sebagai tempat hidup yang tidak akan membahayakan bagi mereka. Beberapa dusun terdekat masuk dalam kawasan kerja Perhutani. Mereka bekerja untuk mengelola tanaman kopi dan karet dan memiliki tempat tinggal di wilayah bawah yang lebih aman. Ketika ada himbauan untuk mengungsi mereka tidak keberatan karena merasa tidak ada yang perlu diperjuangkan atau dilindungi.

Saat sosialisasi dengan warga di Desa Gunosari Kecamatan Tlogosari, Bondowoso, pihak BPBD memberikan bukti bahwa wilayah mereka termasuk daerah aliran lahar. Namun masyarakat memaknai aliran lahar tersebut sebagai aliran darah akibat peperangan Dhamar Wulan dan Menak Jinggo. Mitos ini menjadi keyakinan ketika berbaur dengan pengalaman generasi pendahulu pada erupsi Raung tahun 1956. Mereka yakin tidak perlu mengungsi karena erupsi Raung merupakan letusan dalam kawah saja dan tidak akan keluar.

Berikut adalah rangkuman dari pemaknaan dari masyarakat di ketiga Gunungapi di atas.

Tabel 3. Pemaknaan Ancaman Gunungapi Sebelum dan Sesudah Erupsi

\begin{tabular}{|l|l|l|}
\hline \multicolumn{1}{|c|}{ Kelud } & \multicolumn{1}{c|}{ Bromo } & \multicolumn{1}{c|}{ Raung } \\
\hline \multicolumn{1}{|c|}{ Sebelum Erupsi } \\
\hline $\begin{array}{l}\text { Kepentingan untuk melindugi } \\
\text { ternak bercampur dengan } \\
\text { keyakinan bahwa Desa } \\
\text { mereka aman membentuk } \\
\text { makna bahwa mengungsi } \\
\text { merupakan hal yang tidak } \\
\text { diperlukan }\end{array}$ & $\begin{array}{l}\text { Bromo merupakan Gunungapi } \\
\text { suci yang memberikan berkah } \\
\text { pada kehidupan mereka }\end{array}$ & $\begin{array}{l}\text { Generasi muda diberikan } \\
\text { pemahaman oleh genarasi } \\
\text { sebelumnya bahwa erupsi tidak } \\
\text { akan membahayakan }\end{array}$ \\
\hline $\begin{array}{l}\text { Kayakinan bahwa dengan } \\
\text { meningkatkan religiusitas } \\
\text { akan mengurangi risiko } \\
\text { bencana di masa yang akan } \\
\text { datang }\end{array}$ & $\begin{array}{l}\text { Tuhan mengingatkan mereka } \\
\text { bahwa harus selalu bersyukur } \\
\text { dengan segala nikmat yang } \\
\text { didapatkan }\end{array}$ & $\begin{array}{l}\text { Akumulasi dari pengalaman } \\
\text { erupsi 2015 dan pengetahuan } \\
\text { dari generasi sebelumnya } \\
\text { membangun makna bahwa }\end{array}$ \\
\hline
\end{tabular}

Sumber: Pengolahan Data Primer

\section{Pengelolaan Risiko Erupsi Masyarakat Lokal}

Kesimpulan dari pemaknaan masyarakat terhadap ancaman Gunungapi didapatkan bahwamayorias bersikap nrimo. Mereka berpendapat bahwa apa yang terjadi di masa sekarang dan yang akan datang merupakan kehendak Tuhan. Mereka yang tinggal di sekitar Gunungapi selalu menggantungkan kehidupan mereka pada ekologinya.
Sikap ini terbentuk dari keterikatan pada tanah kelahiran. Mereka mengaku bahwa sulit meninggalkan tanah kelahiran. Meski bencana terjadi atau ada ancaman bencana yang akan terjadi kami akan tetap kembali ke tanah kelahiran.keintiman hubungan antara manusia dan alam ini membangun "insting" dalam mengahadapi bencana. Mereka lebih meyakini tanda dari alam sebagai peringatan untuk mengungsi. Seperti, (1) Hewan-hewan yang turun menandakan bahwa di daerah atas 
semakin panas karena magma yang naik ke permukaan. (2) Suara gemuruh dari atas yang menandakan bahwa akan ada aliran lahar dingin. Dan (3) suara gemuruh dari perut bumi yang menandakan bahwa Gunungapi sedang batuk dan jika batuknya sudah keluar maka tidak akan terjadi masalah.

Pasca erupsi mereka juga memiliki pengetahuan dalam mengelola bencana, yaitu. (1) Prinsip nrimoingpandum, segala sesuatu merupakan keputusan oleh Tuhan. Bencana juga merupakan bagian dari hidup. Mereka perlu mensyukuri bahwa masih diberi kesempatan untukhidup. Dan (2) mangan ra mangan sing penting kumpul, asal mereka bisa berkumpul setelah bencana itu merupakan berkah yang perlu disyukuri. Prinsip ini membangun rasa kebersamaan dalam menghadapi bencana.

Pada fase pemulihan pasca bencana masyarakat Desa Ngadas merupakan masyarakat yang paling tangguh. Sikap nrimo yang ada dalam kehidupan mereka membuat pemulihan pasca erpsi semakin cepat. Pada masyarakat di Kecamatan Ngantang terbentuk sebuah ikatan yang kuat antara warganya. Rasa senasibsepenanggungan membuat kegiatan pemulihan dilakukan bersama-sama. Berikut adalah aspek-aspek yang menjadi acuan dalam pengelolaan erupsi masyarakat lokal seperti terlihat pada Tabel 4.

Tabel 4. Respon Masyarakat dalam Menghadapi Bencana Erupsi Gunungapi

\begin{tabular}{|c|c|c|c|}
\hline & $\begin{array}{l}\text { Erupsi Gunungapi } \\
\text { Kelud tahun } 2014\end{array}$ & $\begin{array}{l}\text { Erupsi Gunungapi } \\
\text { Bromo tahun } 2014\end{array}$ & $\begin{array}{l}\text { Erupsi Gunungapi } \\
\text { Raung tahun } 2015\end{array}$ \\
\hline \multicolumn{4}{|l|}{ Sebelum erupsi } \\
\hline SumberInformasi & Pengamatanlangsung & $\begin{array}{l}\text { BPBD, ritualmalam, } \\
\text { mimpi }\end{array}$ & Pengamatanlangsung \\
\hline Aktor/Pelaku & BPBD & BPBD,kepalaadat & BPBD \\
\hline & & (dukun)dan kepaladesa & \\
\hline IngatanLetusanterakhir & Ingatanlangsung,2010 & Ingatanlangsung,2010 & $\begin{array}{l}\text { Ingatanlangsung, dalam } \\
\text { bukutertulis } 1956\end{array}$ \\
\hline \multicolumn{4}{|l|}{ SaatErupsi } \\
\hline $\begin{array}{l}\text { TindakanPenyelamatan } \\
\text { diri }\end{array}$ & $\begin{array}{l}\text { Pengecekankebenarani } \\
\text { nformasi }\end{array}$ & & $\begin{array}{l}\text { Pengecekankebenaran } \\
\text { informasi }\end{array}$ \\
\hline $\begin{array}{l}\text { TindakanPenyelamatan } \\
\text { Keluarga }\end{array}$ & Menungguinstruksi & - & Menungguinstruksi \\
\hline $\begin{array}{l}\text { TindakanPenyelamatan } \\
\text { LingkunganSosial }\end{array}$ & $\begin{array}{l}\text { Salingmengingatkanda } \\
\text { nberbagiinformasi }\end{array}$ & $\begin{array}{l}\text { Introspeksiperbuatanya } \\
\text { ngpernahdilakukan }\end{array}$ & - \\
\hline \multicolumn{4}{|l|}{ Setelah Erupsi } \\
\hline Kesantentangerupsi & KebesaranTuhan & & Tidakmembahayakan \\
\hline $\begin{array}{l}\text { Pengalamandipengung } \\
\text { sian }\end{array}$ & $\begin{array}{l}\text { Kebersamaandenganp } \\
\text { arakorbanlainnya }\end{array}$ & - & - \\
\hline $\begin{array}{l}\text { Kehadiranaktor/pranata } \\
\text { sosial }\end{array}$ & $\begin{array}{l}\text { Koordinasipenyaluranb } \\
\text { antuantidaktertatadeng } \\
\text { anbaik }\end{array}$ & - & - \\
\hline Penataanhidup & $\begin{array}{l}\text { Kejelasaninformasidant } \\
\text { atakelolapertanian,pete } \\
\text { rnakan,danpemulihans } \\
\text { aranadanprasarana }\end{array}$ & $\begin{array}{l}\text { Wargasecaramandiribe } \\
\text { rgotongroyongmemban } \\
\text { gunkembalikehidupan }\end{array}$ & - \\
\hline
\end{tabular}

Sumber: Pengolahan Data Primer 


\section{Kesimpulan}

Pengetahuan lokal masyarakat tentang Gunungapi memiliki dua makna, yaitu sebagai pemberi kehidupan dan mengambil kehidupan. Sedangkan pada pengetahuan modern hanya memandang Gunungapi sebagai pengambil kehidupan (bencana). Mereka yang tinggal sejak lahir di sekitarnya sudah menganggapnya sebagai bagian dari kehidupan. Meski saat erupsi mengambil semua yang dimiliki. Mereka akan kembali lagi ke tanah kelahirannya. Ikatan ini dimaknai sebagai bentuk hubungan manusia dengan alam.

Beberapa Gunungapi memiliki nilai kultus tersendiri bagi warganya. Mereka beranggapan bahwa Gunungapi tidak akan menyakiti mereka dan memberikan mereka kehidupan dengan warisan abu (tanah yang subur) bagi anak cucunya. Jika bencana terjadi hingga ada korban, itu dimaknai sebagai pengingat bahwa mereka kurang bersyukur atas nikmat yang diberikan atau telah melakukan perbuatan yang buruk.

\section{Daftar Pustaka}

Call, C. M. (2012). Viewing a Word of Disaster Through the Eyes of Faith: The Influence of Religious World.

Dove, M. R., \& Hudayana, B. (2011). Vulnerability in Indonesia. Retrieved from

www.elsevier.com/locate/geoforum

Heller, K., Alexander, D. B., Gatz, M., \& Knight, B. G. (2005). Social and Personal Factors as Predictors of Earthquake Preparation: the Role of Support Provision, Network Discussion, Negative Affect, Age, and Education. Journal of Applied Social Psychology, 3(5), 399-422.

Izadikhah, Y. O. (2004). Bridging the Generation: A Critical Assesment of Disaster Education in the Development of a Seismic Safety Culture in Iran. Cranfield University, Shivenham, UK.

Lindell, M. K., \& Perry, R. . (2000).
Household Adjustment to Earthquake Hazard: A Review of Research. Environment and Behavior, 32, 461501.

Maarif, S. (2012). Kontestasi Pengetahuan dan Pemaknaan Tentang Ancaman Bencana Alam (Studi Kasus Ancaman Bencana Gunungapi Merapi). Jurnal Penanggulangan Bencana, 3(1), 1-13.

Menard, L. A., Slater, R. O., \& Flaitz, J. (2011). Disaster Preparedness and Educational Attainment. Journal of Emergency Management, 9, 45-52.

Miceli, R., Sotgiu, I., \& Settanni, M. (2008). Disaster Preparedness and Perception of Flood Risk: A Study in Analpine Valley in Italy. Journal of Environmental Psychology, 28, 164173.

Mishra, S., \& Suar, D. (2007). Do Lessons People Learn Determine Disaster Cognition and Preparedness? Psychology \& Developing Societies, 19, 143-159.

Muttarakan, R., \& Pothisiri, W. (2013). The Role of Education on Disaster Preparedness: Case Study of 2012 Indian Ocean Earthquakes onThailand's Andaman Coast. Ecology and Society, 18(4), 51-61.

Petal, M. A. (2008). Formal And Informal Education for Disaster Risk

Reduction. In The International Conference on School Safety. Islamabad.

Purnomo, A. (2015). Study of Gender in Adaptation Strategies Post Kelud Volcano Eruption 2014. In International Conference on Sociology Education. Bandung: Universitas Pendidikan Indonesia.

Reininger, B. M., Rahbar, M. H., Chen, M. Lee, Z., Alam, S. R., Pope, J., \& Adams, B. (2013). Social Capital and Disaster Preparedness among Low Income Mexican Americans in a Disaster Prone Area. Social Science and Medicine, 83, 50-60.

Russell, L. A., Goltz, J. D., \& Bourque, L. B. (1995). Preparedness and Hazard Mitigation Actions Before and After Two Earthquakes. Environment and Behavior, 27, 744-770.

Sattler, D. N., Kaiser, C. F., \& Hittner, J. B. 
(2000). Disaster Preparedness:

Relationships among Prior

Experience, Personal Characteristics, and Distress. Journal of Applied Social Psychology, 30, 1396-1420.

Sugiyono, P. D. (2012). Metode Penelitian Kuantitatif, Kualitatif, dan R\&D. bandung: alfabeta.

Tekeli-Yesil, S., Dedeoglu, N., Tanner, M., Braun, C., Fahrlaender, \& Obrist, B. (2010). Individual Preparedness and Mitigation Actions for a Predicted Earthquake in Istanbul. Disaster, 34, 910-930.

Vazquez, E., \& Marvan, M. L. (2012). Volcanic Risk Perception, Locus of Control, Stress and Coping Responses of People Living Near the Popocatepetl Volcano in Mexico. Journal of Risk Analysis and Crisis Response, 2(1), 03-12.

Zamroni, M. I. (2011). Islam dan Kearifan Lokal dalam Penanggulangan

Bencana di Jawa. Jurnal Penanggulangan Bencana, 2(1), 110. 